\title{
INDEX TO VOLUME 68
}

\section{RESEARCH ANNOUNCEMENTS}

Adams, J. F. Vector fields on spheres, 39.

Alfsen, E. M. The optimal Lebesgue-Radon-Nikodym inequality, 230.

Auslander, Louis and Hahn, F. J. Discrete transformations on tori and flows on solvmanifolds, 614.

Bass, Hyman and Schanuel, S. The homotopy theory of projective modules, 425.

Battle, Joseph; Harary, Frank and Kodama, Yukihiro. Every planar graph with nine points has a nonplanar complement, 569.

Battle, Joseph; Harary, Frank; Kodama, Yukihiro and Youngs, J. W. T. Additivity of the genus of a graph, 565.

Baumert, Leonard, Golomb, S. W. and Hall, Marshall, Jr. Discovery of an Hadamard matrix of order $92,237$.

Baumslag, Gilbert. A non-hopfian group, 196.

Baumslag, Gilbert and Solitar, Donald. Some two-generator one-relator non-hopfian groups, 199.

Beckenbach, E. F. and Hutchison, G. A. Meromorphic minimal surfaces, 519.

Bellman, Richard and Karush, William. On the maximum transform and semigroups of transformations, 516.

Blattner, R. J. On a theorem of G. W. Mackey, 585.

Block, H. D. and Fuchs, W. H. J. Acknowledgement, 428.

Blumenthal, R. M.; Getoor, R. K. and McKean, H. P., Jr. Markov processes with identical hitting distributions, 372.

Boone, W. W. Partial results regarding word problems and recursively enumerable degrees of unsolvability, 616.

Bott, Raoul. A note on the KO-theory of sphere bundles, 395.

de Branges, Louis. Entire functions and integral transforms, 103.

Brickman, Louis. Some convolution algebras of measures on $[1, \infty)$ and a representation theorem for Laplace-Stieltjes transforms, 459.

Browder, F. E. On approximation by solutions of partial differential equations, 36. On analyticity and partial differential equations, 454.

Browder, William. Fiberings of spheres and $H$-spaces which are rational homology spheres, 202.

de Bruijn, N. G. and Wilf, H. S. On Hilbert's inequality in $n$ dimensions, 70.

Cargo, G. T. A connection between Tauberian theorems and normal functions, 400.

Carlitz, Leonard. Some theorems on permutation polynomials, 120.

A note on the Jacobi theta formula, 591.

Carlson, David and Schneider, Hans. Inertia theorems for matrices: The semi-definite case, 479.

Chacon, R. V. Operator averages, 351.

Resolution of positive operators, 572.

Chang, C. C. and Keisler, H. J. Model theories with truth values in a uniform space, 107.

Charnes, Abraham, Cooper, W. W. and Kortanek, K. O. A duality theory for convex programs with convex constraints, 605 .

Chen, K.-T. An expansion formula for differential equations, 341.

Cheney, E. W. and Goldstein, A. A. Tchebycheff approximation in locally convex spaces, 449. 
Chung, K. L. and Ornstein, D. S. On the recurrence of sums of random variables, 30. Church, P. T. Differentiable open maps, 468.

Conner, P. E. and Floyd, E. E. Differentiable periodic maps, 76.

Cooper, W. W. See Charnes, Abraham.

Cramér, Harald. On the maximum of a normal stationary stochastic process, 512.

Crawley, Peter. An infinite primary abelian group without proper isomor phic subgroups, 463.

Curtiss, J. H. Solution of the Dirichlet problem by interpolating harmonic polynomials, 333.

Dreben, Burton, Kahr, A. S. and Wang, Hao. Classification of AEA formulas by letter atoms, 528.

Edmonds, Jack. Covers and packings in a family of sets, 494.

Edwards, C. H., Jr. Products of pseudo cells, 583.

Eisenberg, Edmund. Supports of a convex function, 192.

Erdélyi, Arthur. Singular perturbations, 420.

Floyd, E. E. See Conner, P. E.

Fuchs, W. H. J. See Block, H. D.

Getoor, R. K. See Blumenthal, R. M.

Goldberg, S. I. and Kobayashi, Shoshichi. The conformal transformation group of a compact homogeneous Riemannian manifold, 378.

Goldstein, A. A. See Cheney, E. W.

Golomb, S. W. See Baumert, Leonard.

Gray, J. W. Category-valued sheaves, 451.

Hahn, F. J. See Auslander, Louis.

Hall, Marshall, Jr. See Baumert, Leonard.

Hanson, D. L. On the representation problem for stationary stochastic processes with trivial tail field, 115.

Harary, Frank. See Battle, Joseph.

Helgason, Sigurdur. Some results on invariant theory, 367.

Heller, Alex and Reiner, Irving. On groups with finitely many indecomposable integral representations, 210.

Hirsch, M. W. On the product of a contractible topological manifold and a cell, 588.

Hörmander, Lars. Differentiable operators with nonsingular characteristics, 354.

Hutchison, G. A. See Beckenbach, E. F.

Hyllengren, Anders. On the quotient of entire functions of lower order less than one, 340.

Irwin, M. C. Combinatorial embeddings of manifolds, 25.

Jones, F. B. On the existence of a small connected open set with a connected boundary, 117.

Kahr, A. S. See Dreben, Burton.

Karlin, Samuel and McGregor, James. Determinants of orthogonal polynomials, 204.

Karush, William. See Bellman, Richard.

Keisler, H. J. See Chang, C. C.

Kesten, Harry, Ornstein, D. S. and Spitzer, F. L. A general property of random walk, 526.

Kobayashi, Shoshichi. Homogeneous Riemannian manifolds of negative curvature, 338. See Goldberg, S. I.

Kodama, Yukihiro. See Battle, Joseph.

Koecher, M. On real Jordan algebras, 374.

König, Heinz. A theorem on topological maps, 638. 
Kortanek, K. O. See Charnes, Abraham.

Kosinski, A. A. Singularities of piecewise linear mappings. I. Mappings into the real line, 110.

Krabbe, G. L. Generalized measures whose values are operators into an intermediate space, 42.

Kunze, R. A. On the irreducibility of certain multiplier representations, 93.

Lax, P. D. and Phillips, R. S. The wave equation in exterior domains, 47.

Lax, P. D., Morawetz, C. S. and Phillips, R. S. The exponential decay of solutions of the wave equation in the exterior of a star-shaped obstacle, 593.

deLeeuw, Karel and Mirkil, Hazleton. Algebras of differentiable functions, 411.

Levin, Frank. Solutions of equations over groups, 603.

Lewittes, Joseph. Invariant quadratic differentials, 320.

Lindenstrauss, Joram. On the extension property for compact operators, 484.

Liu, Teng-sun. On vanishing algebras, 123.

Lumer, Gunter. Isometries of Orlicz spaces, 28.

Luxemburg, W. A. J. Two applications of the method of construction by ultrapowers to analysis, 416.

Mahowald, Mark. On extending cross sections in orientable $V_{k+m, m}$ bundles, 596.

Marshall, L. C. Approximately continuous transformations on compact metric spaces, 488.

Masani, P. R. Isometric flows on Hilbert space, 624.

Mazur, Barry. Simple neighborhoods, 87.

McGregor, James. See Karlin, Samuel.

McKean, H. P., Jr. See Blumenthal, R. M.

Mirkil, Hazleton. See deLeeuw, Karel.

Morawetz, C. S. See Lax, P. D.

Nohel, J. A. Some problems in nonlinear Volterra integral equations, 323.

Nomizu, Katsumi and Ozeki, Hideki. On the degree of differentiability of curves used in the definition of the holonomy group, 74 .

Ornstein, D. S. See Chung, K. L.

See Kesten, Harry.

Ozeki, Hideki. See Nomizu, Katsumi.

Papakyriakopoulos, C. D. A reduction of the Poincaré conjecture to other conjectures, 360.

Phillips, R. S. See Lax, P. D.

Protter, M. H. Asymptotic behavior of solutions of hyperbolic inequalities, 523.

Rauch, H. E. The singularities of the modulus space, 390.

Reifenberg, E. R. On the tangential properties of surfaces, 213.

Reiner, Irving, See Heller, Alex.

Rice, J. R. Tchebycheff approximation in a compact metric space, 405.

Rieger, G. J. Solution of the Waring-Goldbach problem for algebraic number fields, 234.

Rota, G.-C. Addendum to "On the eigenvalue of positive operators," 49. An "Alternierende Verfahren" for general positive operators, 95.

Roy, Prabir. Failure of equivalence of dimension concepts for metric spaces, 609.

Sario, Leo. Analytic mappings between arbitrary Riemann surfaces, 633.

Schaefer, H. H. and Walsh, B. J. Spectral operators in spaces of distributions, 509.

Schanuel, S. See Bass, Hyman.

Schechter, Martin. Some $L^{p}$ estimates for partial differential equations, 470.

Schmidt, W. M. Simultaneous approximation and algebraic independence of numbers, 475. 
Schneider, Hans. See Carlson, David.

Sherman, Seymour. Combinatorial aspects of the Ising model for ferromagnetism. II. An analogue to the Witt identity, 225.

Sobczyk, Andrew. Extension properties of Banach spaces, 217.

Solitar, Donald. See Baumslag, Gilbert.

Spitzer, F. L. See Kesten, Harry.

Stallings, John. Groups with infinite products, 388.

Stein, E. M. The characterization of functions arising as potentials. II, 577.

Stolzenberg, Gabriel. Polynomially convex sets, 382.

Sucheston, Louis. A zero-one property of mixing sequences of events, 330.

Swanson, C. A. On spectral estimation, 33.

Tamura, Takayuki. Certain characterization of singular semigroups, 402. Note on $\Gamma^{*}$-semigroups, 505.

Treves, François. The equation $\left(\frac{1}{4}\left(\partial^{2} / \partial x^{2}+\partial^{2} / \partial y^{2}\right)+\left(x^{2}+y^{2}\right) \partial^{2} / \partial t^{2}+(x \partial / \partial y\right.$ $-y \partial / \partial x) \partial / \partial t)^{2} u+\partial^{2} u / \partial t^{2}=f$, with real coefficients, is "without solutions," 332,655$)$.

Tutte, W. T. A new branch of enumerative graph theory, 500 .

Ullman, J. L. Tchebycheff quadrature is possible on the infinite interval, 574.

Varadarajan, V. S. On a problem in ergodic theory, 345.

Walsh, B. J. See Schaefer, H. H.

Wang, Hao. See Dreben, Burton.

Wilf, H. S. See de Bruijn, N. G.

Youngs, J. W. T. See Battle, Joseph.

\section{RESEARCH PROBLEMS}

Bellman, Richard. Calculus of variations-differential equations, 68.

Differential equations of threshold type, 69.

Number theory, 179.

- Number theory-generalized cyclotomic sums, 179.

Prediction theory, 180.

Probability theory, 180.

Cheney, E. W. and Curtis, P. C., Jr. Convex bodies, 305.

Church, P. T. and Hemmingsen, Erik. Topology, 68.

Classical Function Theory Problems, 21.

Curtis, P. C., Jr., See Cheney, E. W.

Harary, Frank. Matrix theory, 21.

Hemmingsen, Erik. See Church, P. T.

Shen, Mok-Kong and Shen, Tsen-Pao. Number theory, 557.

Shen, Tsen-Pao. See Shen, Mok-Kong.

Wallace, A. D. Problems concerning semigroups, 447.

\section{BOOK REVIEWS}

Aczél, J. and Gołab, S. Funktionalgleichungen der Theorie der geometrischen Objekte. Albert Nijenhuis, 552.

Aleksandrov, P. S. Combinatorial topology. Vol. 3. Ky Fan, 555.

Artin, Emil. Theory of algebraic numbers. L. J. Mordell, 162.

Auslander, Maurice. See Zariski, Oscar.

Bergman, Stefan. Integral operators in the theory of linear partial differential equations. Erwin Kreyszig, 161.

Birkhoff, Garrett. See von Neumann, John.

Blumenthal, R. M. See Dynkin, E. B. 
Boas, R. P., Jr., A primer of real functions. I. S. Gál, 10.

Chung, K. L. See Rosenblatt, Murray.

Coxeter, H. S. M. Introduction to geometry. Hans Freudenthal, 55.

Dinghas, Alexander. Vorlesungen ïber Funktionentheorie. Maurice Heins, 311.

Dubreil, P. J. and Dubreil-Jacotin, M. L. Leçons d'algèbre moderne. G. B.Seligman, 18.

Dubreil-Jacotin, M. L. See Dubreil, P. J.

Dynkin, E. B. Theory of Markov processes and Die Grundlagen der Theorie der Markoffschen Prozesse. R. M. Blumenthal, 176.

Erdélyi, Arthur. See Kratzer, A.

Fan, Ky. See Aleksandrov, P. S.

Finn, Robert, See von Mises, Richard.

Franz, W. See Kratzer, A.

Freudenthal, Hans. See Coxeter, H. S. M. See van der Waerden, B. L.

Gál, I. S. See Boas, R. P., Jr.

Gillman, Leonard and Jerison, Meyer. Rings of continuous functions. Edwin Hewitt, 173.

Gołab, S. See Aczél, J.

Green, Leon. See Laugwitz, Detlef.

Halmos, P. R. See Jacobs, Konrad.

Hartman, S. and Mikusinski, J. The theory of Lebesgue measure and integration. J. C. Oxtoby, 548.

Heins, Maurice. See Dinghas, Alexander.

Heller, Alex. See Hocking, J. G.

Hewitt, Edwin. See Gillman, Leonard.

Hocking, J. G. and Young, G. S. Topology. Alex Heller, 308.

Isbell, J. R. See Kowalsky, H.-J.

Jacobs, Konrad. Neuere Methoden und Ergebnisse der Ergodentheorie. P. R. Halmos, 59.

Jerison, Meyer. See Gillman, Leonard.

Khinchin, A. Y. Mathematical foundations of quantum statistics. G. W. Mackey, 169. Kowalsky, H.-J. Topologische Räume. J. R. Isbell, 68.

Kratzer, A. and Franz, W. Transzendente Funktionen. Arthur Erdélyi, 51.

Kreyszig, Erwin. See Bergman, Stefan.

Laugwitz, Detlef. Differential geometrie. Leon Green, 313.

Letov, A. M. Stability in nonlinear control systems. Lawrence Markus, 545.

Mackey, G. W. See Khinchin, A. Y.

Markus, Lawrence. See Letov, A. M.

Mikusinski, J. See Hartman, S.

von Mises, Richard. Mathematical theory of compressible fluid flow. Robert Finn, 549.

Mordell, L. J. See Artin, Emil.

Nehari, Zeev. Introduction to complex analysis. George Springer, 310.

von Neumann, John. Continuous geometry. Garrett Birkhoff, 61.

Nijenhuis, Albert. See Aczél, J.

Noshiro, Kiyoshi. Cluster sets. Wladimir Seidel, 551.

Ostrowski, A. M. Solution of equations and systems of equations. D. M. Young, Jr., 306.

Oxtoby, J. C. See Hartman, S.

Rad6, T. and Reichelderfer, P. V. Continuous transformations in analysis. J. W. T. Youngs, 13. 
Reichelderfer, P. V. See Rad6, T.

Robinson, G. de B. Representation theory of the symmetric group. A. H. Wallace, 166.

Rosenblatt, Murray. Random processes. K. L. Chung, 445.

Samuel, Pierre. See Zariski, Oscar.

Schild, Alfred. See Synge, J. L.

Seidel, Wladimir. See Noshiro, Kiyoshi.

Seligman, G. B. See Dubreil, P. J.

Springer, George. See Nehari, Zeev.

Synge, J. L. Relativity: The general theory. Alfred Schild, 167.

van der Waerden, B. L. Science awakening. Hans Freudenthal, 543.

Wallace, A. H. See Robinson, G. de B.

Young, D. M., Jr. See Ostrowski, A. M.

Young, G. S. See Hocking, J. G.

Youngs, J. W. T. See Radó, T.

Zariski, Oscar and Samuel, Pierre. Commutative algebra. Vol. II. Maurice Auslander, 12.

\section{REPORTS OF MEETINGS AND MISCELLANEOUS ARTICLES}

By-Laws of the American Mathematical Society, 647.

Council and Board of Trustees-1961, 50.

Endowment Funds of the Society, 644.

Green, J. W. See Youngs, J. W. T.

Green, J. W. and Pitcher, Everett. Reports of Meetings of the American Mathematical Society: The April Meeting in Atlantic City, 316.

Huff, G. B. Reports of Meetings of the American Mathematical Society: The November Meeting in Gainesville, 63.

Manual for Authors of Mathematical Papers, 429.

Meder, A. E., Jr. Report of the Treasurer, 65.

Pierce, R. S. Reports of Meetings of the American Mathematical Society: The November Meeting in Santa Barbara, 64; The April Meeting in Monterey, 319; The Summer Meeting in Vancouver, 558.

Pitcher, Everett. Reports of Meetings of the American Mathematical Society: The October Meeting in Cambridge, 24; The February Meeting in New York, 191. See Green, J. W.

Representatives and Committees of the Society, 641.

Youngs, J. W. T. Reports of Meetings of the American Mathematical Society: The November Meeting in Milwaukee, 62; The April Meeting in Chicago, 315.

Youngs, J. W. T. and Green, J. W. Reports of Meetings of the American Mathematical Society: The Annual Meeting in Cincinnati, 181.

\section{INVITED ADDRESSES}

Anderson, R. D., 63.

Beaumont, R. A., 319.

Chow, W. L., 181.

Dwork, B. M., 181.

Gehring, F. W., 62.

Helson, Henry, 64.

Ito, Noboru, 315.

Iwasawa, Kenkichi, 181.

Jenkins, J. A. The general coefficient theorem and certain applications, 1. 
Keller, J. B., 316.

Kervaire, Michel, 24.

Kostant, Bertram, 181.

Loewner, Charles, 558.

Lowdenslager, D. B., 316.

Lin, C. C., 558.

Morrey, C. B., 181.

Some recent developments in the theory of partial differential equations, 279.

Moser, J. K., 181.

Nelson, Edward, 181.

Nijenhuis, Albert, 558.

Palais, R. S., 191.

Pierce, R. S., 558.

Röhrl, Helmut, 62.

Holomorphic fiber bundles over Riemann surfaces, 125.

Stoker, J. J. Some observations on continuum mechanics with emphasis on elasticity, 239.

Vaught, R. L., 558.

Wallace, A. H., 315.

A geometric method in differential topology, 533.

Wermer, John. Uniform approximation and maximal ideal spaces, 298.

Yang, C. N., 181. 